\title{
Commentary: Risk prediction model on adult congenital heart surgery. And more...
}

\author{
Katsuhide Maeda, $\mathrm{MD}, \mathrm{PhD},{ }^{\mathrm{a}}$ and George K. Lui, $\mathrm{MD}^{\mathrm{b}}$
}

From the Departments of ${ }^{\mathrm{a} C a r d i o t h o r a c i c ~ S u r g e r y ~ a n d ~}{ }^{\mathrm{b}}$ Cardiology, Stanford University School of Medicine, Stanford, Calif.

Disclosures: Authors have nothing to disclose with regard to commercial support.

Received for publication Aug 13, 2019; revisions received Aug 13, 2019; accepted for publication Aug 14, 2019; available ahead of print Oct 25, 2019.

Address for reprints: Katsuhide Maeda, MD, PhD, Department of Cardiothoracic Surgery, Stanford University, 300 Pasteur Drive, Stanford, CA 94305 (E-mail: kmaeda@stanford.edu).

J Thorac Cardiovasc Surg 2020;159:2416-7

$0022-5223 / \$ 36.00$

Copyright (c) 2019 by The American Association for Thoracic Surgery

https://doi.org/10.1016/j.jtcvs.2019.08.111

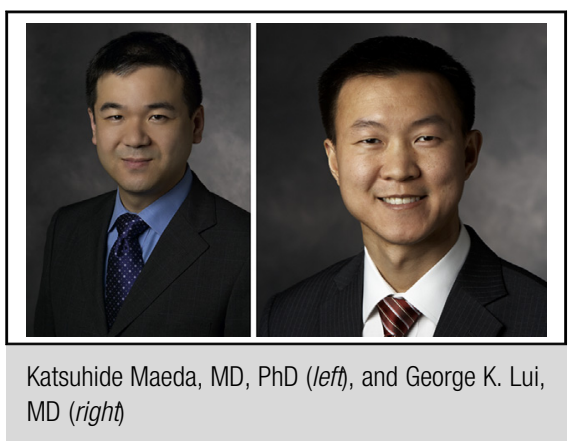

Central Message

A risk prediction model for adult CHD surgery has significant impact on decision making in management of these patients and sheds light on initial surgeries at childhood as well as current surgical planning.

See Article page 2407. these patients are different from adults with acquired heart disease undergoing cardiac surgery. Lei Lei and colleagues ${ }^{2}$ studied 784 consecutive adults with CHD and concluded that risk factors for postoperative adverse outcomes included MELD-XI score, cognitive impairment, number of chest wall incisions, body mass index, and cardiac anatomic category. In addition, 1-year mortality was predicted by need for anticoagulation, MELD-XI score, and cardiac anatomic category.

This risk model sheds light on the importance of preoperative management planning. Congenital heart surgeons should be aware of these risks and the importance of a multidisciplinary team in the comprehensive evaluation of adults with CHD undergoing cardiac surgery. Furthermore, it is recommended that adults with CHD be evaluated and cared for in regional adult CHD programs, where specialized care has been associated with improved survival. $^{3}$

Liver disease is highly prevalent following surgical repair in adults with CHD. Residual lesions such as tricuspid or pulmonary regurgitation, atrial shunts, or Fontan obstruction, which can result in high hepatic venous pressure, should be intervened on early because patients with Child-Pugh B class liver cirrhosis have a $66 \%$ 1 -year mortality in the setting of cardiac surgery. ${ }^{4}$ In patients with cirrhosis of the liver, combined heart and liver transplant may be an acceptable alternative rather than conventional surgery in adults with CHD. ${ }^{5}$

Although anticoagulation is mandatory in some patients, such as those with a Fontan circulation, any condition such as arrhythmia or mechanical valve that requires

anticoagulation should be carefully prevented. Body mass index has a nonlinear, U-shaped curve where efforts to improve malnutrition or weight loss should be corrected before surgery. In terms of the number of chest wall incisions, advanced imaging including assessment of peripheral vasculature may aid the surgeon in re-entry. Restricted lung function from chest wall deformities, difficulty opening due to scar tissue, or multiple blood product use due to bleeding are potential associations. If restricted lung function is the primary cause, avoiding thoracotomy that causes chest deformity or minimally invasive surgery should be considered. Likewise, instead of the use of multiple blood products, perhaps bloodless surgery can improve outcomes.

Finally, the authors concluded that cardiac anatomy other than biventricular subaortic left ventricle is adversely related to outcome. This is intuitively understandable, but we lack a detailed risk prediction model for specific CHD and surgical repair. In addition, it is imperative these types of risk scores be validated in multicenter, prospective, outcomes-based cohorts of patients with adult CHD. The need for risk prediction models in cardiac surgery that include not only the anatomy and previous interventions but also comorbidities and clinical characteristics of adults with CHD is clear, and this study provides early insight into some of these unique features. 


\section{References}

1. Lui GK, Saidi A, Bhatt AB, Burchill LJ, Deen JF, Earing MG, et al American Heart Association Adult Congenital Heart Disease Committee of the Council on Clinical Cardiology and Council on Cardiovascular Disease in the Young, Council on Cardiovascular Radiology and Intervention, Council on Quality of Care and Outcomes Research. Diagnosis and management of noncardiac complications in adults with congenital heart disease: a scientific statement from the American Heart Association. Circulation. 2017;136:e348-92.

2. Lei Lei E, Ladja K, Mueller B, Roche L, Rao V, et al. Noncardiac determinants of death, intensive care morbidity in adult congenital heart disease surgery. J Thorac Cardiovasc Surg. 2020;159:2407-15.e2.
3. Stout KK, Daniels CJ, Aboulhosn JA, Bozkurt B, Broberg CS, Colman JM, et al 2018 AHA/ACC guideline for the management of adults with congenital heart disease: executive summary: a report of the American College of Cardiology/American Heart Association task force on clinical practice guidelines. Circulation. 2019;139:e637-97.

4. Jacob KA, Hjortnaes J, Kranenburg G, de Heer F, Kluin J. Mortality after cardiac surgery in patients with liver cirrhosis classified by the Child-Pugh score. Interact Cardiovasc Thorac Surg. 2015;20:520-30.

5. Vaikunth S, Concepcion W, Daugherty D, Fowler M, Lutchman G, Maeda K, et al Outcome of en bloc combined heart and liver transplantation in the adolescent and adult failing Fontan. Clin Transplant. 2019;33:e13540. 